\title{
Fuel Analysis of Jatropha Methyl Ester and n-Tridecane as an Alternative Fuel for the Future
}

\author{
Annisa Bhikuning ${ }^{1,2}$, Eriko Matsumura ${ }^{1}$ and Jiro Senda ${ }^{1}$ \\ ${ }^{1}$ Doshisha University, Mechanical Engineering Department, 1-3 tatara Miyakodani, Kyotanabe City Kyoto 610-0394, Japan \\ ${ }^{2}$ Trisakti University, Mechanical Engineering Department, Jl. Kyai Tapa No.1, Grogol Jakarta Barat 11440, Indonesia
}

\begin{abstract}
The authors proposed for new fuel between blending of jatropha methyl ester and n-tridecane. Biodiesel has an advantage in reducing emissions. Nevertheless, it has high viscosity and density and has poor spray characteristics compared to diesel fuel. The blending between n-tridecane would overcome the unwanted fuel properties. The n-tridecane and jatropha methyl ester were blended under three condition; JME25\% (Jatropha Methyl Ester 25\% and n-tridecane 75\%), JME50\% (Jatropha Methyl Ester 50\% and n-tridecane 50\%), and JME75\% (Jatropha Methyl Ester 75\% and n-tridecane 25\%). The fuel properties were analyzed under biodiesel standardization from JIS K and ASTM D. FTIR analyzed also showed the characteristics of carbonyl peak that indicates as methyl ester. In the results, JME50\% had met the requirements for fuel properties from biodiesel standardization.
\end{abstract}

\section{Introduction}

Nowadays, biodiesel has been a warm issue due to its beneficial and its potential to replace fossil fuel in the future. Many researchers have investigated not only edible oil for biodiesel such as palm oil [1], rapeseed [2] but also non-edible oil like jatropha curcas [3] and karanja oil [4]. However, biodiesel from edible oil would confront the competition of feedstock between human's food and fuel. Nevertheless, non-edible oil would be a good alternative since no competition in feedstock between food and fuel.

Biodiesel has advantages for reducing emissions such as $\mathrm{HC}$ as well as SOx in combustion through the fuel properties. Biodiesel may reduce some organic wastes, it can also reduce some pollutants to the environment [5].

In this study, the authors investigated new jatropha methyl ester that fulfills with the standard of biodiesel without blended with diesel fuel. Biodiesel has high viscosity, high density and has poor in spray atomization compared to diesel fuel. In order to overcome the undesirable fuel properties, new material was added. In this study, Jatropha Methyl Ester was blended with ntridecane. Fuel properties and FTIR (Fourier Transform Infrared Spectroscopy) analysis of jatropha methyl ester and n-tridecane were evaluated. The aims of this study were to find the right blending between JME25, JME50, and JME75 that meet the requirements for the new fuel by analyzing some properties and also FTIR.

\section{Methodology}

\subsection{Material and method of the biodiesel blend}

The Jatropha Methyl Ester (JME) was purchased from Revo International, Japan. The n-Tridecane was purchased from Nakalai tesque, Japan. JME were blended with n-tridecane under three conditions, JME 25\%+n-tridecane 75\% (JME25); JME 50\% + ntridecane 50\% (JME50); JME 75\% + n-tridecane 25\% (JME 75).

\subsection{Fuel properties analysis}

The fuel parameter properties were analyzed in Shimadzu Kyoto-Japan used Japan International standard - JIS K based on the method. The density $\left(15^{\circ}\right)$ was determined according to JIS K official method 2249. The kinematic viscosity $\left(40^{\circ}\right)$ was determined under JIS K 2283 . The flash point (PMCC) was analyzed based on JIS K 2265. The Cetane number was analyzed on JIS K 2280. The copper strip corrosion was determined under JIS K 2513. The distillation was analyzed based on JIS K 2254. Nevertheless, $n$-tridecane chemical properties were taken from PubChem data based [6]. The fuel parameter analysis also compared to the ASTM D standard which based on the American and part of Asian biodiesel standardization.

\subsection{FTIR analysis}

The FTIR spectra data were taken using Shimadzu, Iraffinity-1, and FTIR 8400 spectrometer, in the range of $4000-400 \mathrm{~cm}^{-1}$. 


\section{Results and discussion}

\subsection{Fuel analysis}

\subsubsection{Density}

The density in fuel parameter is important to determine. Density is a chemical property to figure the exact volume of fuel to provide a satisfactory combustion [7]. Density can also impact the efficiency of the combustion system and fuel atomization in engine [8]. Biodiesel usually has high in density compared to diesel fuel. In case, the density is high. It can be influenced by engine output power due to distinctive in fuel mass injection [9]. Figure 1 shows that the density in jatropha blending with ntridecane have low values compared to standard JIS K 2249. Nevertheless, the value JME 75 has met the requirements of ASTM D 1298 biodiesel standardization.

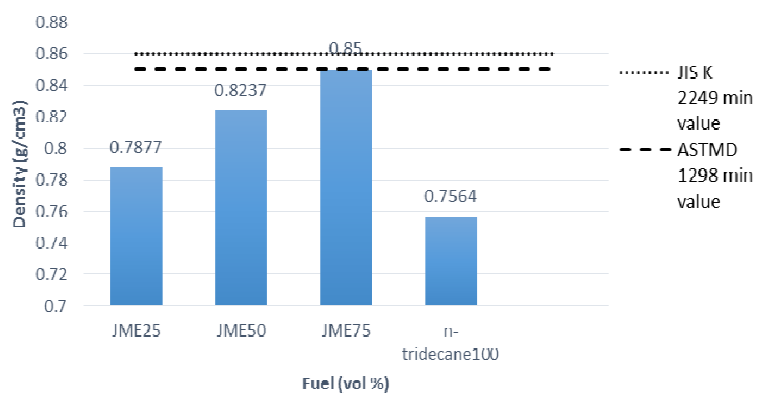

Figure 1. Density in various blends.

\subsubsection{Kinematic viscosity}

The kinematic viscosity in biodiesel has high value compared to diesel fuel, this condition caused by high fatty acid in biodiesel. High in kinematic viscosity can cause poor in the spray automation and can produce deposits in the engine and it can upgrade the energy to pump the fuel [8]. On the contrary, lower in kinematic viscosity would easier the fuel to pump and attain droplets to injector [10]. Demirbas [10] studied that diesel fuel has a similar viscosity with biodiesel. Transesterification process would decrease the viscosity level than pure biodiesel.

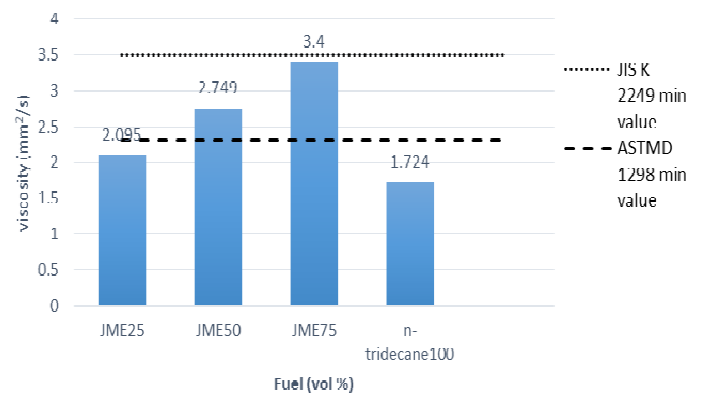

Figure 2. Viscosity in various blends.

From figure 2, the viscosity value of JME50, and JME75 have met the requirement for ASTM D 1298.
Nevertheless, JME25, JME50, and JME75 have under value for JIS K 2249 standardization. However, ntridecane 100 has not met all the standardization for JIS K 2249 nor ASTM D 1298.

\subsubsection{Flash point}

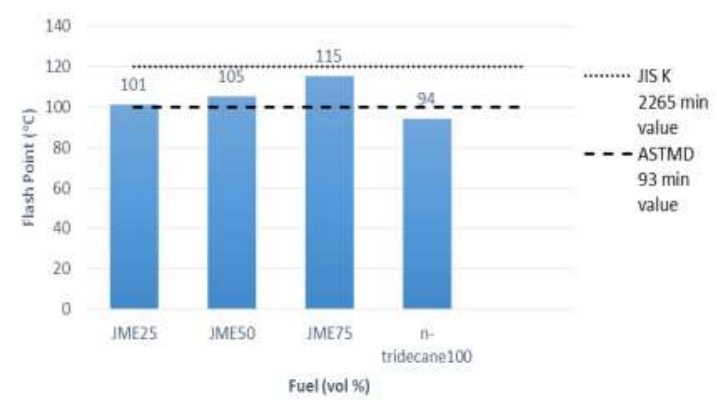

Figure 3. Flash Point in various blends.

The fuel flammability condition is pointed by its flash point. The estimation of flash point diverse and conversely corresponding to the instability of the fuel [11]. The Flash point value of diesel fuel is around 55-66 ${ }^{\circ} \mathrm{C}$. While biodiesel is around $110-180{ }^{\circ} \mathrm{C}$. Biodiesel has its minimum temperature of flash point. The JIS K 2265 has a minimum standard of a flash point that is $120 \mathrm{oC}$. Otherwise, ASTM D 93 has a lower standard of a minimum flash point that is $100^{\circ} \mathrm{C}$.

From figure 3 shows that all fuels have met the biodiesel standard of ASTMD 93. Nevertheless, all fuels have not met the standard of JIS K2265.

\subsubsection{Cetane number}

Figure 4 displays the cetane number of various blends. It shows that all the Fuels have met the requirement for cetane number standards.

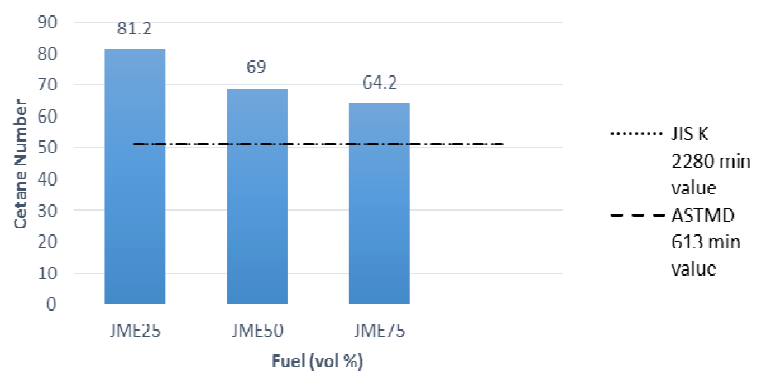

Figure 4. Cetane Number in various blends.

Cetane number is a value that indicates how the fuel will burn completely in the combustion chamber. High cetane number in fuels have several advantages such as the complete combustion will occur in the engine, reduce the knocking and noise in the engine, reduce the warm-up time engine and lower emission during combustion in a safer environment [12].

\subsubsection{Copper strip corrosion}


Copper strip test is to measure the corrosive of sulfur compounds in the fuel. The ASTM D 130 and JIS K 2513 consist of dipping a strip of copper into the fuel for a specified time and define temperature and observing the corrosive action of the fuel [13].

From figure 5 it shows that JME25, JME50, and JME75 have met the standard requirement of JIS K 213 and ASTMD 130. These indicated that JME 25, JME50, and JME75 are safe from the compound of corrosive sulfur.

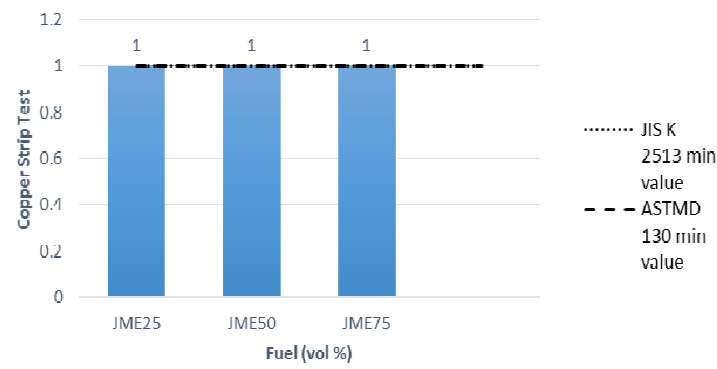

Figure 5. Copper Strip Corrosion from Various Blends.

\subsubsection{Distillation}

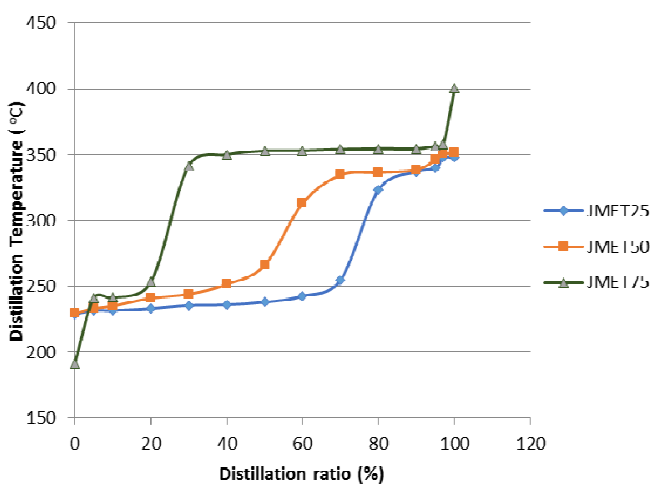

Figure 6. Distillation from various Blends.

The distillation curves can be seen in figure 6 . It shows that JME $75 \%$ has higher volatility than JME $50 \%$ and JME $25 \%$. This indicated that JME $75 \%$ has poor in spray characteristics (bigger droplets) than JME 50\% and JME $25 \%$.

\subsection{FTIR Analysis}

FTIR is Fourier Transform Infrared Spectrometry. Presently, FTIR has been characterized to discover the methyl peak positions from the reaction of transesterification of Biodiesel [14]. FTIR spectrometry is a worth equipment to predict wave numbers in biodiesel samples [15]

\subsubsection{Tridecane}

Tridecane is a combustible fuel. The fuel characteristics from n-tridecane are different from diesel fuel and biodiesel fuel.
The FTIR analysis of $n$-tridecane is shown in figure 7 . In the figure shows there are only three peaks which strong in the FTIR figure. The alkana strong C-H vibration at $2920,23 \mathrm{~cm}^{-1}$, the alkane bending $-\mathrm{C}-\mathrm{H}$ vibration at $1470 \mathrm{~cm}^{-1}$ and the strong alkyl halide $\mathrm{C}-\mathrm{Cl}$ $720 \mathrm{~cm}^{-1}$. This indicated that $\mathrm{n}$-tridecane is not from vegetable oil since no carbonyl peak between 1740-1750 $\mathrm{cm}^{-1}$ [16]. Furthermore, there is no spectral region between $1300-1060 \mathrm{~cm}^{-1}$ which is indicated as methyl ester.

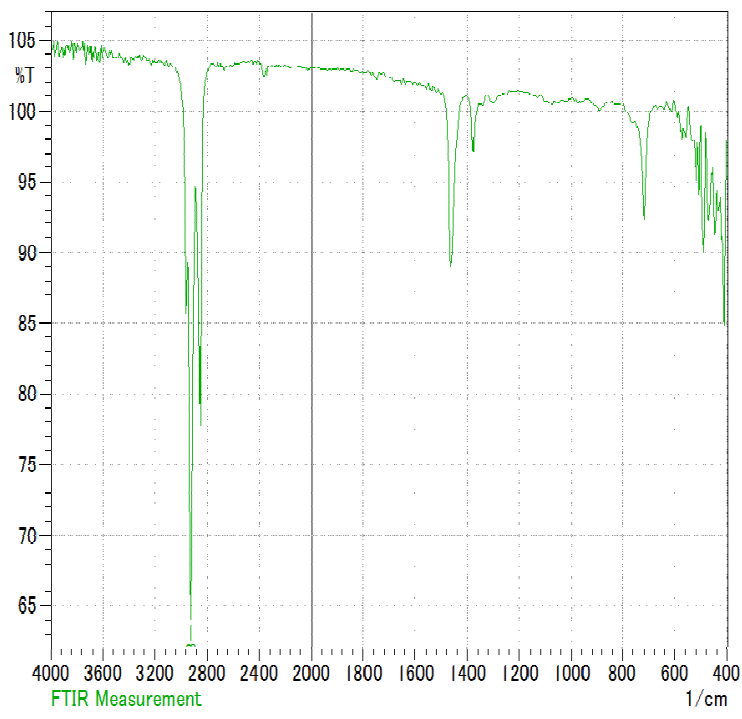

Figure 7. FTIR n-Tridecane.

\subsubsection{JME 25\% (Jatropha Methyl Ester 25\% and n-} Tridecane $75 \%$ )

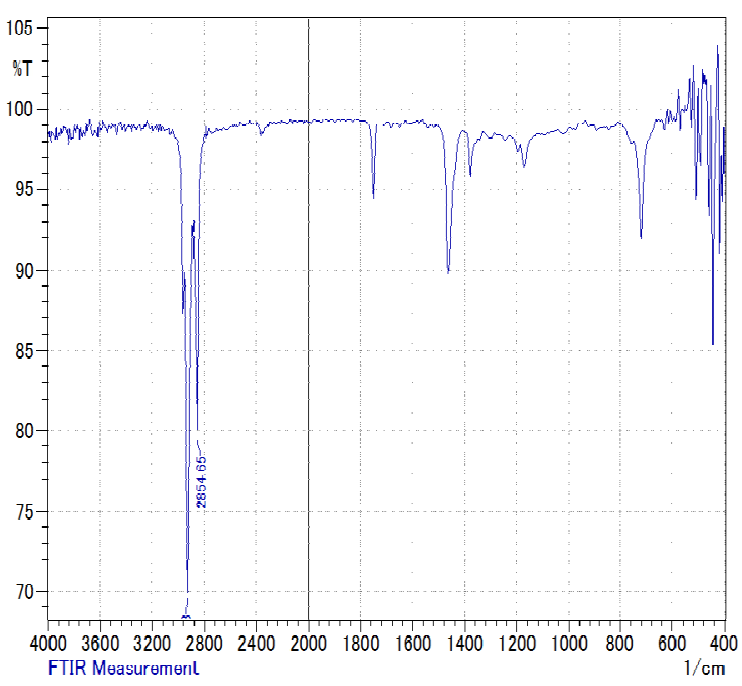

Figure 8. FTIR JME 25\%.

The result of FTIR analysis of JME $25 \%$ is shown in figure 8 . In the figure, there are four peaks from FTIR result. It shows strong band in $\mathrm{C}-\mathrm{H}$ alkane wave number at $2854.65-2920.23 \mathrm{~cm}^{-1}$. The stretch ether $\mathrm{C}=\mathrm{O}$ vibration 
at $1760 \mathrm{~cm}^{-1}$. The alkane bending $-\mathrm{C}-\mathrm{H}$ vibration at 1460 $\mathrm{cm}^{-1}$. The strong alkyl halide $\mathrm{C}-\mathrm{Cl}$ vibration at $720 \mathrm{~cm}^{-1}$.

JME25\% is pointed that the fuel is made from vegetable oil or methyl ester since the $\mathrm{C}=\mathrm{O}$ peak at 1760 has appeared although the wave number is not strong. However, it is correlated that the blend between ntridecane and jatropha methyl ester can be approved from FTIR graph. The strong or weak of wave number have corresponded between the percentage amount of blending between fuel and methyl ester.

\subsubsection{JME 50\% (Jatropha Methyl Ester 50\% and n- Tridecane 50\%)}

From the figure 9 indicates the FTIR result from JME $50 \%$. From the figure there are five strong peaks in FTIR analysis.

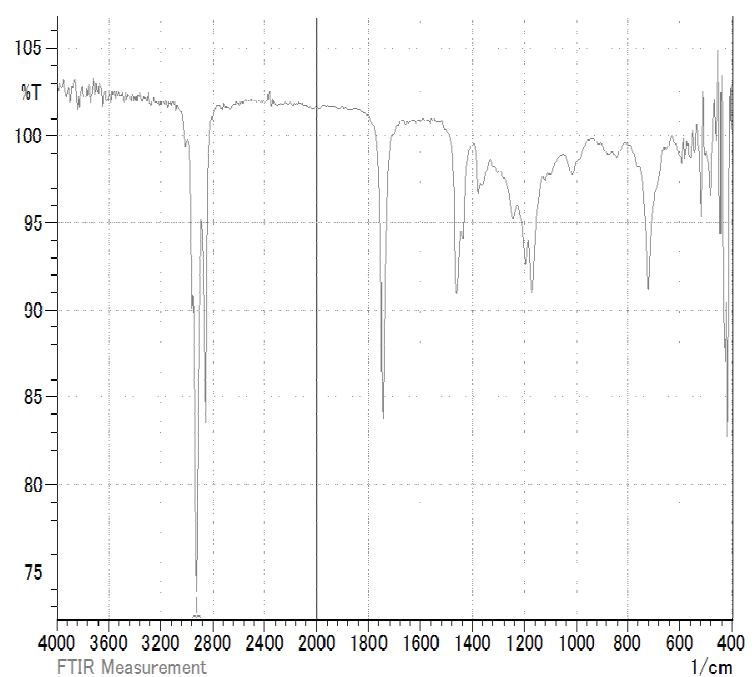

Figure 9. FTIR JME 50\%.

The alkane stretch $\mathrm{C}-\mathrm{H}$ vibration between 2870 $2920,23 \mathrm{~cm}^{-1}$. The strong stretch ether $\mathrm{C}=\mathrm{O}$ and the wave number is at $1750 \mathrm{~cm}^{-1}$. The alkane bending $-\mathrm{C}-\mathrm{H}$ vibration at $1470 \mathrm{~cm}^{-1}$, The ether stretch $\mathrm{C}-\mathrm{O}$ wave number at $1170 \mathrm{~cm}^{-1}$ and the strong alkyl halide vibration at $723 \mathrm{~cm}^{-1}$.

JME $50 \%$ shows that the carbonyl peak is in 1750 which is longer than JME $25 \%$. The methyl ester peak is at 1170 . This pointed that JME $50 \%$ is contained of methyl ester from jatropha, which blended with the higher composition of JME $25 \%$ and n-tridecane.

\subsubsection{JME 75\% (Jatropha Methil Ester 75\% and n- Tridecane 25\%)}

As shown in figure 10, the FTIR analysis of JME $75 \%$ is analyzed. There are five strong peaks in the FTIR figure. The alkane stretch $\mathrm{C}-\mathrm{H}$ vibration at $2870-2920,23 \mathrm{~cm}^{-1}$, the ether $\mathrm{C}=\mathrm{O}$ strong stretch at a wave number of 1750 $\mathrm{cm}^{-1}$, The alkane bending $-\mathrm{C}-\mathrm{H}$ vibration at $1470 \mathrm{~cm}^{-1}$, the ether stretch $\mathrm{C}-\mathrm{O}$ at a wave number of $1170 \mathrm{~cm}^{-1}$ and the strong alkyl halide $\mathrm{C}-\mathrm{Cl}$ at a wave number of $723 \mathrm{~cm}^{-}$ 1 .
From the figure it shows that JME $75 \%$ has indicated from vegetable oil or methyl ester since it has strong carbonyl peak $\left(1750 \mathrm{~cm}^{-1}\right)$ and strong ester C-O (1168.86). Those lines are longer than JME 25\% and JME $50 \%$. This can be proved that JME $75 \%$ was contained large blending proportions between jatropha methyl ester and n-tridecane.

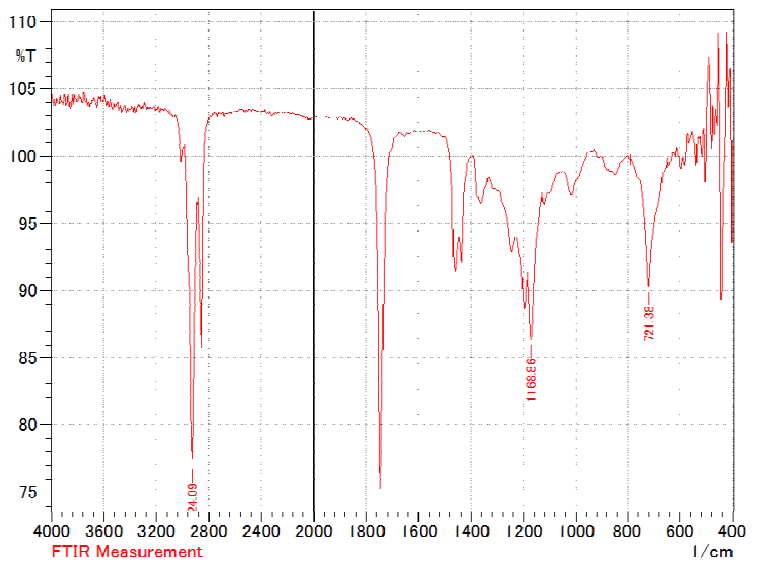

Figure 10. FTIR JME $75 \%$.

\section{Conclusion}

The conclusions from this study are:

1. Fuel analysis of JME $25 \%$, JME $50 \%$ and JME $75 \%$ for cetane number, copper strip corrosion point are and flash point are meet the standardization between ASTM D and JIS K.

2. The Viscosity of JME $50 \%$ and JME $75 \%$ are meet standardization of ASTM D 1298 but not for JIS K 2249.

3. The distillation curves show that JME $75 \%$ has higher volatility than JME $50 \%$ and JME $25 \%$. This would effect for having a poor spray characteristic than JME 50\% and JME 25\%.

4. FTIR analysis of n-tridecane is indicated that no vegetable oil or methyl ester is contained in the fuel. This due to no carbonyl peak between $1740-1750 \mathrm{~cm}^{-1}$ and ester peak between 1060$1300 \mathrm{~cm}^{-}{ }^{1}$.

5. FTIR analysis of JME $25 \%$, JME $50 \%$ and JME $75 \%$ showed that there are numbers of carbonyl peak (1740-1750 $\left.\mathrm{cm}^{-1}\right)$ and ester peak (1060$\left.1300 \mathrm{~cm}^{-1}\right)$. This correlated that the longest line of carbonyl peak would have larger blending between jatropha methyl ester. This proved that JME75\% has the longer line in carbonyl peak than JME $25 \%$ and JME $50 \%$. This can be analyzed that JME 75 is contained $75 \%$ jatropha methyl ester and $25 \%$ of n-tridecane.

6. From the conclusion of fuel analysis, the JME $50 \%$ can be chosen as one of the best alternative fuel for the future. 


\section{Acknowledgement}

The first author would like to grateful for Directorate General of Higher Education Ministry of Education and Culture (DIKTI) as a financial support, Coordination of Private Universities (KOPERTIS) and Prof. Michiaki Matsumoto Lab. Biochemical Engineering Doshisha University, Kyoto Japan.

\section{References}

1. Nongbe MC, Ekou T, Ekou L, Yao KB, Grognec EL, Felpin FX. Biodiesel Production from palm oil using sulfonated graphene catalyst. Renewable Energy. 106,135-141 (2017)

2. Hu Q, Hua W, Yin Y, Zhang X, Liu L, Shi J, Zhao Y, Qin L, Chen C, Wang H. Rapeseed research and production in China. The Crop Journal. 5, 127-135 (2017)

3. Rattanaphra D, Srinophakun P. Biodiesel production from crude sunflower oil and crude jatropha oil using immobilized lipase. Journal of Chemical Engineering of Japan. 43, 104-108 (2010)

4. Meher LC, Kulkarni MG, Dalai AK, Naik SN. Transesterication of karanja (Pongamia pinnata oil by solid basic catalysts. European Journal of Lipid Science and Technology. 108, 3898-3978 (2006)

5. Ikegami M. The use of fatty acid methyl ester called biodiesel fuel. Meeting for investigation into the actual conditions for diesel exhaust gas emission with alternative fuels. JSAE (2002)

6. https://pubchem.ncbi.nlm.nih.gov/compound/Trideca ne
7. Ramirez V, Luis F. Density and viscosity of biodiesel as a function of temperature: empirical models. Renewable and Sustainable Energy Reviews. 19, 652-665 (2013)

8. Xua J, Grift TE, Hansen AC. Effect of biodiesel on engine performances and emissions. Renewable Energy Reviews. 15, 1098-1116 (2011)

9. E.Alptekin, M. Canaksi. Determination of the density and the viscosities of biodiesel-diesel fuel blends, Renewable Energy. 33, 2623-2630 (2008).

10. Demirbas A. Progress and recent trends in biodiesel fuels. Energy Conversion and Management. 50 ,1434 (2009)

11. A.S. Silitonga et al. Overview properties of biodiesel diesel blends from edible and non-edible feedstock. Renewable and Sustainable Energy Reviews. 22, 346-360 (2013)

12. http://farmweeknow.com/blogs-benefits-high-cetanediesel-fuel-3681

13. Knothe G. Analyzing biodiesel: standards and other methods. JAOCS.83,823-833 (2006)

14. Barone JR. $233^{\text {rd }}$ ACS National meeting. Paper AGRO-153.Chicago.25-29 (2007)

15. Cunha CL, Luna AS, Oliveira RCG, Xavier GM, Paredes MLL, Torres AR. Predicting the properties of biodiesel and its blends using mid-FTIR spectrometry and first-order multivariate calibration. Fuel.204,185-194 (2017)

16. Zhang WB. Review on analysis of biodiesel with infrared spectroscopy. Renewable and sustainable energy reviews. 16, 6048-6058 (2012) 